Contract No. and Disclaimer:

This manuscript has been authored by Savannah River Nuclear Solutions, LLC under Contract No. DE-AC09-08SR22470 with the U.S. Department of Energy. The United States Government retains and the publisher, by accepting this article for publication, acknowledges that the United States Government retains a non-exclusive, paid-up, irrevocable, worldwide license to publish or reproduce the published form of this work, or allow others to do so, for United States Government purposes. 


\section{DEVELOPMENT OF ASME SECTION X CODE RULES FOR HIGH PRESSURE COMPOSITE HYDROGEN PRESSURE VESSELS WITH NON-LOAD SHARING LINERS}

\author{
Norman L. Newhouse, Ph.D., P.E. \\ Vice President, Technology \\ Lincoln Composites, Inc. \\ $5117 \mathrm{NW} 40^{\text {th }}$ Street \\ Lincoln, NE 68524 \\ nnewhouse@lincolncomposites.com \\ Tel: 402-470-5035
}

\author{
George B. Rawls, P.E. \\ Senior Fellow Engineer \\ Savannah River National Laboratory \\ Building 773-41A, Room 173 \\ Aiken, SC 29808 \\ george.rawls@srnl.doe.gov \\ Tel: 803-725-5658
}

\author{
Mahendra D. Rana, P.E. \\ Engineering Fellow \\ Praxair, Inc. \\ 175 East Park Drive \\ Tonawanda, NY 14151 \\ Mahendra_Rana@Praxair.com \\ Tel: $\overline{7} 16-879-2408$
}

\author{
Bernard F. Shelley, P.E. \\ Sr. Consultant \\ DuPont Engineering Company \\ PO Box 80722 \\ Wilmington, DE 19880 \\ bernard.f.shelley@usa.dupont.com \\ Tel: 302-999-2593
}

\author{
Michael R. Gorman, Ph.D. \\ President \\ Digital Wave Corporation \\ 6555 S. Kenton Street, Suite \\ 304 \\ Centennial, CO 80111 \\ mgorman@digitalwavecorp.com
}

Tel: 303-790-7559

\begin{abstract}
The Boiler and Pressure Vessel Project Team on Hydrogen Tanks was formed in 2004 to develop Code rules to address the various needs that had been identified for the design and construction of up to 15000 psi hydrogen storage vessel. One of these needs was the development of Code rules for high pressure composite vessels with non-load sharing liners for stationary applications. In 2009, ASME approved new Appendix 8, for Section X Code which contains the rules for these vessels. These vessels are designated as Class III vessels with design pressure ranging from $20.7 \mathrm{MPa}(3,000 \mathrm{ps}) \mathrm{i}$ to 103.4 MPa (15,000 psi) and maximum allowable outside liner diameter of $2.54 \mathrm{~m}$ (100 inches). The maximum design life of these vessels is limited to 20 years. Design, fabrication, and examination requirements have been specified, included Acoustic Emission testing at time of manufacture. The Code rules include the design qualification testing of prototype vessels. Qualification includes proof, expansion, burst, cyclic fatigue, creep, flaw, permeability, torque, penetration, and environmental testing.
\end{abstract}

\subsection{INTRODUCTION}

ASME recognized a need to develop Code requirements to support the Hydrogen Economy, and formed its Hydrogen Steering Committee in 2002 to outline the necessary steps for planning and coordinating this effort. The Boiler and Pressure Vessel Project Team on Hydrogen Tanks was formed in 2004 to develop Code rules to address the various needs that had been identified. One of these needs was the development of Code requirements for high pressure composite vessels with non-load sharing liners for stationary applications. The Project Team was able to draw on experience from design and use of ASME Section X vessels, cylinders to transport compressed gases, and fuel containers for natural gas and hydrogen powered vehicles as it developed these new Code requirements.

The work of the Project Team was initially developed as a Code Case. When the Code Case was being drafted, the Project Team felt that the natural home for the case was in Section X, which covers composite pressure vessels with nonload sharing liners. The only problem is that the scope of Section X only went to $20.7 \mathrm{MPa}$ (3,000 psig). In order to incorporate the Code Case into Section X it would be necessary to increase the scope of Section $\mathrm{X}$ to a new class of vessel up to 103.4 MPa (15,000 psig). 
The Code Case was reviewed in Section $\mathrm{X}$ but there were concerns about the case as written. It was decided to go ahead and incorporate a Code revision in the form of a mandatory Appendix 8 which would incorporate the principle parts of the Code Case, but also incorporate more Section $\mathrm{X}$ requirements.

The combined change of scope and Appendix 8 was first balloted in June of 2009 but failed at the committee level due to the desire to incorporate a more robust testing criteria for these high pressure vessels since they used a much lower design factor than currently used for Section X vessels.. The committee felt that acoustic emission testing was warranted for these vessels.

The existing acoustic emission criteria used in Section $\mathrm{X}$ was not suitable for the configuration of these vessels, and a task group was set up with several testing consultants to formulate a new criteria. The task group met through the summer of 2009 and formulated a revised testing criteria that was incorporated into in draft Appendix 8.

The revised Appendix 8 and change of scope was reballoted in September 2009 and was approved by Section X in November 2009. It was the balloted by the TOMC and approved in December of 2009. The change of scope and Appendix 8 will be published in the 2010 edition of Section X.

These vessels are designated as Class III vessels with design pressure ranging from $20.7 \mathrm{MPa}$ (3,000 psi) to 103.4 $\mathrm{MPa}(15,000 \mathrm{psi})$ and maximum allowable outside liner diameter of 100 inches. The maximum design life of these vessels is limited to 20 years. Design, fabrication, and examination requirements have been specified, included Acoustic Emission testing at time of manufacture.

The Code rules include the design qualification testing of prototype vessels. Qualification includes proof, expansion, burst, cyclic fatigue, creep, flaw, permeability, torque, penetration, and environmental testing. This paper presents the description and technical basis for Appendix 8, Section X Code rules.

\subsection{INDUSTRY BACKGROUND}

There is significant experience within the composite pressure vessel industry, including the use of Codes and Standards, that has been considered when developing the Code Rules for the new ASME Section X Class III pressure vessels [1].

The origin of fiber reinforced pressure vessels traces to the development of glass fiber reinforced pressure vessels in the 1950's. This led to use of composite pressure vessels in other military applications, and then to aerospace and commercial applications. Commercial use of fiber reinforced pressure vessels began in the 1970's, and the number of applications continues to grow today.

Three of the primary areas of use are stationary vessels, where ASME has developed Code Rules, transportable cylinders, where agencies such as DOT-PHMSA have jurisdiction, and vehicle fuel containers, where agencies such as DOT-NHTSA have jurisdiction.

\subsection{ASME Section X Class I Vessels}

Section X Class I vessels are mass produced and machine made. The design is qualified by the destructive testing of a prototype vessel and cyclic testing to 100,000 full range pressure cycles. Maximum design pressure is limited to 20.7 MPa (3,000 psig) and maximum design temperature is limited to $120^{\circ} \mathrm{C}\left(250^{\circ} \mathrm{F}\right)$. Class 1 vessels may have fiberglass, metallic or thermoplastic liners. The design margin has been established at 6.0 (5.0 for polar boss vessels) against burst.

One representative application for Section $\mathrm{X}$ Class $\mathrm{I}$ vessels is for use as hydraulic accumulators in the tensioning systems for off-shore oil platforms (Fig. 1) [21]. This application falls under the jurisdiction of the U.S. Department of Interior, Minerals Management Service (DOI/MMS). Pressure vessels used on oil platforms are generally qualified under the ASME Boiler and Pressure Vessel Code. The light weight and corrosion resistance of a Section $\mathrm{X}$ all-composite cylinder offers life-cycle cost savings.

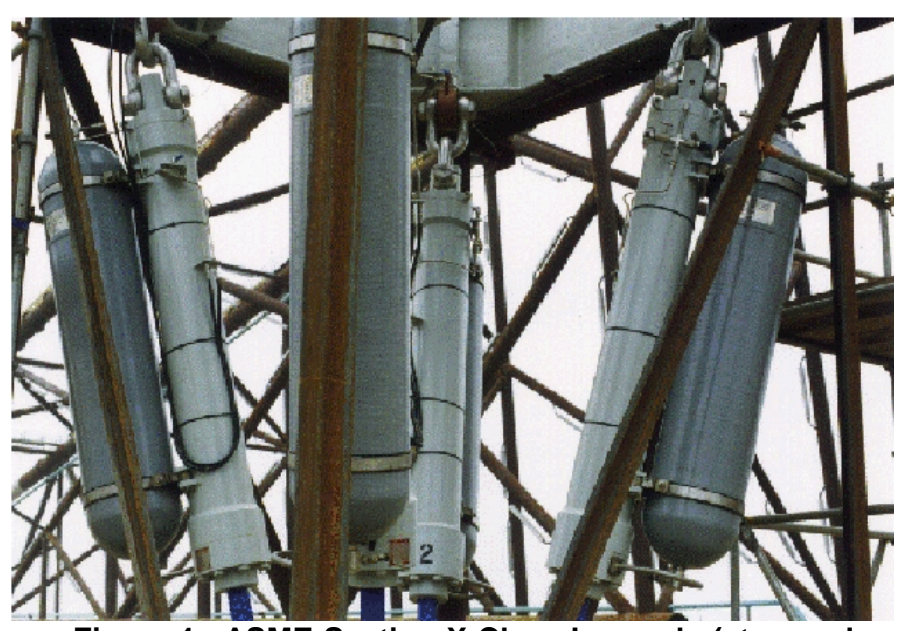

Figure 1. ASME Section X Class I vessels (strapped to hydraulic cylinders)

These accumulators range in diameter from $440 \mathrm{~mm}(17.3$ inches) to $510 \mathrm{~mm}$ (20.1 inches), and have lengths from $2.10 \mathrm{~m}$ (82 inches) to $2.650 \mathrm{~m}$ (104 inches). Volumes range from 190 liters (50 gallons) to 330 liters (87 gallons).

These composite accumulators have been provided for several platforms to date, including Mars, Ram Powell, Marlin, Ursa, and Brutus. A total of over 500 cylinders have been delivered for these applications.

Another application for Section X Class I vessels is in the water treatment area where they are used for carbon beds, reverse osmosis vessels for desalinization and water purification plants. Such vessels can operate at up over 6.9 MPa (1,000 psig) and range from $150 \mathrm{~mm}$ (6 inches) inner diameter to over $1200 \mathrm{~mm}$ (48 inches) inner diameter. Such vessels make the vast majority of Section $X$ vessels that are 
manufactured.

\subsection{ASME Section X Class II Vessels}

Section X Class II vessels are custom fabricated and are generally used in the chemical and petrochemical industries as storage and processing vessels. Vessels as large as $3.65 \mathrm{~m} \mathrm{(12}$ feet) in diameter by over $15.24 \mathrm{~m}$ (50 feet) in length have been built Class II vessels are limited to $1.73 \mathrm{MPa}$ (250 psig) and maximum design temperature of $120^{\circ} \mathrm{C}\left(250^{\circ} \mathrm{F}\right)$. The design margin is normally 10.0 against burst. Class II vessel designs must be computed using design rules or laminate theory given in Section X and the vessel must be acoustic emission tested during the hydrotest to prove its acceptability.

\subsection{Transportable Cylinders}

Transportable cylinders must be approved through issuance of Special Permits in the United States since DOTPHMSA has no regulations for composite pressure vessels. Commonly referenced standards for this jurisdiction include FRP1, developed by the Compressed Gas Association, CFFC, developed by DOT-PHMSA, and ISO 11119.

Typical applications include emergency breathing cylinders, such as for firemen and for mine safety, and escape slide inflation for large commercial aircraft. Other applications include pressurant tanks for paint ball guns, and liquefied propane gas (LPG) tanks. There are over 3 million high pressure composite cylinders, and over 2 million composite propane cylinders, in use worldwide.

Large vessels for storage and transport of compressed natural gas and hydrogen have recently been developed, with support from the US Department of Energy. These vessels are approximately $1.07 \mathrm{~m}$ (42 inches) in diameter and $11.7 \mathrm{~m}$ (38.5 feet) long, with four being mounted in an $40 \times 8 \times$ 8-foot ISO frame (Fig. 2). As they can be used for both transportation and ground storage of compressed gases, they would be an good choice to be qualified to the ASME Section X Class III Code requirements.

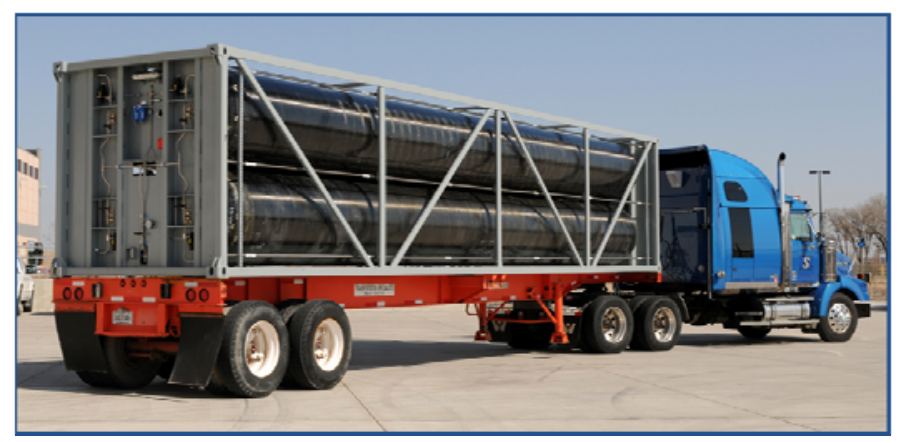

Figure 2. Large Composite Pressure Vessels

\subsection{Vehicle Fuel Containers}

Composite vessels have been used as fuel containers for motor vehicles running on compressed natural gas and hydrogen. There are about 125,000 vehicles using these composite containers in North America. Automobiles may use only one cylinder per vehicle, but trucks and buses use more, up to eight or ten containers per vehicle. Containers in the United States must meet the requirements of FMVSS 304 (49 CFR 571.304), and are generally designed to meet the requirements of ANSI/CSA NGV2 in the United States, or ISO 11439 internationally.

Compressed natural gas fuel containers generally operate at pressures of 20.7 MPa (3,000 psi) and 24.8 MPa (3,600 psi). Hydrogen fuel containers generally operate at pressures of 24.8 $\mathrm{MPa}, 35 \mathrm{MPa}$, and $70 \mathrm{MPa}$ (3,600 psi, 5,075 psi, and 10,150 psi). Sizes range up to $560 \mathrm{~mm}$ (22 inches) in diameter and $3.05 \mathrm{~m}$ (10 feet) in length. These cylinders have also been used stationary cascades and in tube trailers.

\subsection{ASME SECTION X APP 8 CODE RULES}

ASME Section X Appendix 8 for Class III vessels was developed as noted in section 3.0 of this paper. Consideration was given to each of the standards mentioned in section 4.0 of this paper, along with the requirements of ASME Code Case 2579, when developing the requirements of Section X Appendix 8.

The following sections discuss the new Rules for Class III vessels and provide some background rationale for key requirements.

\subsection{Scope of Section X Appendix 8}

The new code requirements for high pressure hydrogen storage vessels were written to support the Department of Energy program to develop codes and standards needed to support an infrastructure for a hydrogen economy. The basis data indicated that a hydrogen powered vehicle would have tank capacity of $69 \mathrm{MPa}(10,000 \mathrm{psi})$. The need for hydrogen storage vessels was set at $103 \mathrm{MPa}(15,000 \mathrm{psi})$ to meet the need for high pressure refueling. The current rules in Section $\mathrm{X}$ provided requirements for vessel construction to $20.7 \mathrm{MPa}$ (3,000 psi) without restriction on fluid service. The Appendix 8 scope is applied to hydrogen vessels with design pressures not less than $21 \mathrm{MPa}(3000 \mathrm{psi})$ or greater than $103 \mathrm{MPa}$ $(15,000 \mathrm{psi})$.

The filament winding technique was chosen for the fabrication method because it provides for vessels with a high fiber volume fractions and controlled fiber orientation, resulting in the most efficient designs for high pressure services. In filament winding, laminate containing continuous multi-directional filaments is circumferentially and longitudinally wound (helical pattern) in a systematic manner under controlled tension over the cylindrical shell and heads of a liner.

The initial Appendix 8 requirements address the requirements for CPVs with non-load sharing liners. The nonload bearing liner case was developed first because the majority of the industrial Manufacturers' supporting this effort design 
and fabricate CPVs with non-load sharing liners. Additional rules are now under development to address CPVs with load sharing liners.

In the non-load sharing case the laminate is designed to carry the entire pressure load. A maximum liner load fraction of less than 10 percent of the nominal burst pressure of the finished CPV is the cutoff value for non-load sharing liners. The load share value of 10 percent or less of burst was determined to be at a level such that yielding of the liner, in an overpressure condition, would not result in a significant redistribution of load to the laminate.

The non-loading sharing rules allow for both metallic and non-metallic liners. The initial work by the hydrogen project team was to develop rules for metallic vessels in high pressure hydrogen service. The metallic effort resulted in an additional section to Section VIII, Division 3.

Article KD-10, "Special Requirements for Vessels in High Pressure Gaseous Hydrogen Transport and Storage Service" was developed to provide additional requirements to the code to address the fracture mechanics requirements needed to address hydrogen embrittlement in steels [3].

These rules for metallic material are applied to address any load bearing metallic parts in Appendix 8 such as the nozzle or bosses for the Composite Pressure Vessels (CPV).

Permeation of the hydrogen through the liner needed to be specifically addressed for the non-metallic material. Data for the most common liner material, polyethylene, was specifically reviewed. Qualification testing was included to address concerns about hydrogen permeation in the liners.

The project team was charged with developing code requirements for vessels for a hydrogen infrastructure so the resulting Section X, Appendix 8 scope was limited to hydrogen services. Because of the small molecule size, resulting in leakage issues, hydrogen is one of the most difficult fluids to contain. There are no technical issues with applying the Appendix 8 rules to other inert or flammable gases. If rules are needed for toxic or oxidizing gases additional requirements may be needed.

The new Appendix 8 rules require that the outside diameter of the metallic or nonmetallic liner shall not exceed 100 in (2.5 $\mathrm{m})$. The size limit is somewhat arbitrary since there is not a technical limit controlling the size of a CPV. The 100 in (2.5 $\mathrm{m})$ diameter approaches the size limit where shipping starts to become an issue. The other more important limit on size is fabrication. There are few manufacturing facilities available with capacity to produce CPVs of this size.

The new Appendix 8 requirements focus on the infrastructure needs for a hydrogen economy. The need to provide large hydrogen storage and transport capacity was defined in the charter of the project team. Other codes and standard development organizations are developing requirements for portable and vehicle tanks.

The Appendix 8 requirements are limited to stationary service. The restriction to stationary service did result in reduced qualification testing because the drop testing common to many CPV specifications are not included in the Appendix 8 requirements.

It is the expectation of the Hydrogen Project Team that these larger diameter stationary vessels would be transported and handled with critical procedures. Damage to a CPV during transport or drop would be treated no differently for the CPV than for any other Section VIII vessel, which would require fitness for service evaluations following such an accident.

Metallic and composite $103 \mathrm{MPa}(15,000 \mathrm{psi})$ hydrogen vessels are clearly needed for transport applications to support a hydrogen infrastructure. For applications in the US these requirements would require DOT-PHMSA acceptance. The transport requirements are clearly in the initial charter of the project team.

At the current time it is unclear whether the project team will develop the transport requirements. It is envisioned that the transport requirements would include both required loads and load combinations for all modes of transport. Additional qualification testing would also be required for performance based standards for transport conditions.

Maximum service life for CPV constructed under the rules of Appendix 8 shall be limited to twenty (20) years from the date of manufacture. The service life of the CPV shall be as specified in the User's Design Specification. The service life has increased in recent years in consensus standards from 15 to 20 years. The project team developed a report on CPV inspection to provide guidance for in-service inspection [4]. Further extension of design life above twenty years will require better inspection techniques to be developed.

\subsection{General Requirements}

The Manufacturer is responsible for preparation of a Manufacturing Specification to control materials and essential variables during the manufacturing process. The specific essential variables are addressed in section 3.5 below.

The Manufacturing Specification is the controlling document for all material specifications for metallic and nonmetallic liner components and laminate materials. All tolerances on critical vessel dimensions and tolerances on fabrication parameters are defined in the Manufacturing Specification.

While the metallic components are required to be fabricated from code approved material, the non-metallic components are not code listed material. Therefore, the required chemistry and physical and mechanical properties for the material forming the laminate are required to be documented in the Manufacturing Specification.

The Manufacturing Specification also has a parallel function to the ASME Section IX welding procedures and welding qualification process in controlling the essential variables for the filament winding process.

It is also the Manufacturer's responsibility to conduct Qualification Tests as outlined in Section 3.7 below. Since this standard is performance based these qualification tests form the 
design basis for a specific vessel design. The vessel performance is also a function of the essential variables defined in the Manufacturing Specification.

To maintain quality control during production the essential variables defined in the manufacturing specification must be monitored during production.

The Manufacturer is also required to conduct production examinations and tests. The results of all testing and examinations shall be documented in the Qualification Test Report. The Qualification Test Report shall be prepared and certified by the Manufacturer and accepted by the Inspector. The test results are required to be included in the Manufacturer's Construction Records.

The Manufacturer is required as part of the ASME accreditation process to contract an independent inspection agency to monitor quality control. The Authorized Inspector shall carry out inspection of the materials and the fabrication process.

The Inspector must be qualified by a written examination under the rules of any state of the United States or province of Canada that has adopted ASME BPV Section X. The Inspector is required to make all examinations required by the requirements in Appendix 8 in addition to the requirements of Section X.

The Inspector is also allowed to perform investigations deemed necessary in his judgment to verify that all material and manufacturing procedures being used conform to the requirements of the Manufacturing Specification When load bearing metallic parts are used, the Inspector shall also perform the examinations required for compliance with the applicable sections of ASME BPV Section VIII Division 3.

\subsection{Materials Requirements}

The structural materials used to manufacture the Section $\mathrm{X}$ Class III are controlled in a manner consistent with existing Codes and Standards.

Metallic components used in the manufacture of the Class III vessel must meet the requirements of Section VIII, Div. 3.

All material used in the manufacture of the laminate must be traceable to an individual Class III vessel and documented in the Fabricator's Construction records.

The laminate consists of a fiber reinforcement in a resin matrix. Glass and carbon fibers are currently allowed. Other fibers might be suitable, but consideration would need to be given as to whether additional testing and Code requirements would be appropriate for them. Resin systems are to be epoxy, polyester, or vinyl ester. These are commonly used in the fabrication of pressure vessels.

Glass fibers may be Type S, Type E, or Type E-CR. Carbon fibers must be from a polyacrylonitrile (PAN) precursor. The material supplier must certify that these fibers conform to the Fabricator's specifications.

When carbon fiber is used, galvanic protection must be provided where metallic materials are contacted. This may be provided by a physical barrier such as glass cloth in a resin matrix, but equivalent methods may also be used.

Viscosity, specific gravity, and either epoxide equivalent (for epoxy) or acid number (for polyester or vinyl ester) property data must be certified.

Component ratios must be set for resin and curing agent in the resin formulation, and must be consistent between the qualification test vessels and production vessels. A maximum use temperature must be established for the resin system.

The laminate must be properly cured, with verification by Barcol hardness or equivalent, such as by checking a resin sample with a differential scanning calorimeter (DSC).

The laminate must have a minimum interlaminar shear strength of 13.8 MPa (2000 psi), determined in accordance with ASTM D2344, following a 24-hour water boil. This verifies that the resin will likely will not break down over the normal use cycle such that the fiber would start to unravel or such that it would not properly transfer load between fibers or layers.

The liner material must be suitable for the gas to be contained, which is hydrogen in the initial implementation of Appendix 8 for Class III vessels. Properties of the liner are confirmed and certified by the material supplier. Since the liner is a non-structural material, specific material requirements are not specified in Appendix 8. The qualification tests verify that the performance of the liner material is adequate.

\subsection{Design Requirements}

A stress analysis is required as part of the fabricators construction records. Non-linear behavior, such as elasticplastic response of a metallic liner, or bending in the dome, must be addressed. Minimum material conditions and geometric irregularities such as out-of-roundness, weld peaking, and weld mismatch must be addressed.

One of the key aspects of the analysis is to confirm that the design does not place the fibers above limits that could result in stress rupture of the fibers. The maximum fiber stress is limited to $28.5 \%$ for glass fiber and $44.4 \%$ for carbon fiber of the tensile strength of the fiber at design conditions. This corresponds to stress ratios, or safety factors, of 3.5 for glass fiber and 2.25 for carbon fiber, and is intended to provide reliability with respect to stress rupture in excess of 0.999999 over the life of the vessel.

Carbon fiber may be operated at a high percent of tensile strength because of its superior stress rupture characteristics [5, 6]. The tensile strength of the fiber must be determined through the use of a burst test of a pressure vessel, and not by using quoted values or strand tensile test results, in order to valid for stress ratio calculations.

Hybrid designs, using both carbon and glass fiber, are allowed. Either both fibers must operate within the stress limits, or one of the fibers must operate within its stress limit if all of the other fiber is removed. 
Hybrid construction can be advantageous, such as when carbon fiber reinforcement is used to provide the principle strength and fatigue resistance, and glass fiber is added to increase wall thickness for damage tolerance. Protective layers may also be applied to the outside of the vessel.

The design pressure is to be specified, within a range of 20.7 MPa (3,000 psi) to 103.4 MPa (15,000 psi). One purpose of the tanks made to Class III requirements is for use as cascades to fill hydrogen fuel cell vehicles. These vehicles now use pressures to $70 \mathrm{MPa}(10,150 \mathrm{psi})$, so a higher pressure was required for the cascade.

A pressure of $103.4 \mathrm{MPa}(15,000 \mathrm{psi})$ was sufficiently above the $70 \mathrm{MPa}(15,000 \mathrm{psi})$ vehicle pressure that a cascade could be efficient, and this pressure was within previously demonstrated capabilities of the industry.

The lower pressure limit of $20.7 \mathrm{MPa}(3,000 \mathrm{psi})$ was consistent with expected use for storage of compressed gases, and results in a wall thickness assuring a minimum level of robustness. It also prevented an overlap of coverage with existing Class I requirements.

The temperature ranges allowable are from -54C (-65F) to $+85 \mathrm{C}(+185 \mathrm{~F})$. These temperatures are generally recognized as the extreme ambient limits to which vessels would be exposed during transportation or operation. The maximum temperature must also be at least 19C (35F) below the maximum use temperature of the resin.

\subsection{Fabrication Requirements}

The Manufacturing Specification specifies all pertinent material property information, information on the winding process, and all other significant process data. It includes tolerance limits on material properties, process conditions, and acceptable test results. The Manufacturer's Specification becomes part of the Fabricator's Construction Records. Variation from the essential variables is not allowed.

The liner, including the nozzles, must have detailed information on materials, including limits of chemical analysis and material properties. The dimensions, including tolerances, of the basic liner and threaded connections must be provided. Process and specification of manufacture, minimum inspection requirements and method of sealing the nozzle to the liner, if not integral, must be provided.

Documentation of the laminate includes fiber materials and mechanical properties, fiber/resin content, resin system components and properties, details of the winding band and its application, and details of the curing process.

Laminate manufacture must be identified, including specific winding patterns, winding tension, and winding speed.

\subsection{Examination Requirements}

The Fabricator is responsible for conducting the examinations. The examiner performing visual tests on Class III vessels must be qualified to the requirements of Section V,
Article 9. The examination must be carried out after the hydrostatic test.

The vessels must be visually examined for imperfections. These imperfections include burned areas, chips, cracks, foreign inclusions, pimples, pits, porosity, scratches, wrinkles and creases, band width gapping, band width overlapping, and band width splaying.

The Class III vessels must be examined for conformance with dimensions and tolerances shown on the design drawings.

Imperfections that are only present in non-structural portions of the laminate may be repaired. Each repaired areas must be examined and meet all requirements.

Thickness, and variation of same, shall be evaluated. It must be verified that the minimum thickness requirements have been met.

After the production hydrotest, the metallic pressure parts meeting the requirements of Section VIII, Division 3 must be subjected to a surface exam in accordance with KE-400. Only the accessible portions of these parts must be examined by liquid penetrant or magnetic particle examination with acceptance criteria per KE-233.2

Acoustic emission examination is required at the time the vessel is being hydrotested. Acoustic emissions are generally copious in number on the first loading of a new vessel. It is well-known that thousands of tiny matrix cracks develop in composite vessels during the initial pressurization as the composite material adjusts to the load. This is in fact beneficial, much as shakedown testing of a metal vessel is beneficial to the metal vessel. The method requires a subsequent pressurization to $98 \%$ of the previous maximum pressure. In the second test, the emissions should be far fewer and no large energy motions (events) should occur.

The test procedure itself is straightforward but care must be taken or the recorded sounds may be noisy, distorted and potentially useless. Sensors are coupled to the vessel and connected to the recording equipment per ASME Sec. V. A pressure transducer is also connected to the recorder. Performance checks are made to verify everything is working properly. The vessel is pressurized, held at pressure, depressurized to $10 \%$ and held for 30 minutes, repressurized to $98 \%$ of the prior pressure, and then depressurized to zero psi. Record events for approximately two minutes at zero psi, if there are any events at zero psi. Save data. A post-test performance check is carried out and the data saved.

Sensor performance checks should be carried out prior to and immediately after the test to verify proper operation and good coupling to the vessel. The gain should be set so the threshold is at $60 \mathrm{~dB}_{\mathrm{AE}}$. The $\mathrm{E}$ and $\mathrm{F}$ waveforms should be observed by breaking pencil lead at approximately $20 \mathrm{~cm}$ and $40 \mathrm{~cm}$ from a sensor along the fiber direction. Save all data.

For the test (the vessel's first pressurization), the gain should be $40 \mathrm{~dB}$ or the value that corresponds to a threshold of $80 \mathrm{~dB}_{\mathrm{AE}}(0 \mathrm{~dB}=1 \mu \mathrm{V}$ at the sensor $)$. Record waveforms during all pressurizations and pressure holds and depressurizations. 
Sensitivity, bandwidth, and signal to noise ratio are dictated by a good measurement of the wave motions created by a fracture mechanism. Noise events, in the sense of unwanted signals from other than fracture sources, are found in most testing situations and must be handled by their shape, spectral characteristics, or other information known about the test such as a temporally associated disturbance due to the pressurization system or test fixturing.

A modern (>3 GHz) PC usually has sufficient speed and memory to keep up with the data rate in most tests, however this is affected by the number of recorder channels, the sample length, and sampling rate. The test pressure must be recorded simultaneously with the AE events. Permanent storage of the waveforms is required.

The computer program must be capable of detecting the first arrival channel in a multi-channel arrangement. This is critical to the acceptance criteria as discussed below. Computer algorithms may be used to automate the analysis but examination of the waveforms event by event by an expert must always be possible and the waveforms for each event must correspond precisely with the pressure and time data during the test.

The specific analysis of this procedure, shape of the cumulative events versus time, is guided by the reasoning of weakest link fiber strength theories, shear lag and load sharing models of composite behavior, as well as past experience with Code tests in ASME Section V, X and ASTM 2191. This is mainly a composite stability test. An example of a stable vessel is given in Figures 3.

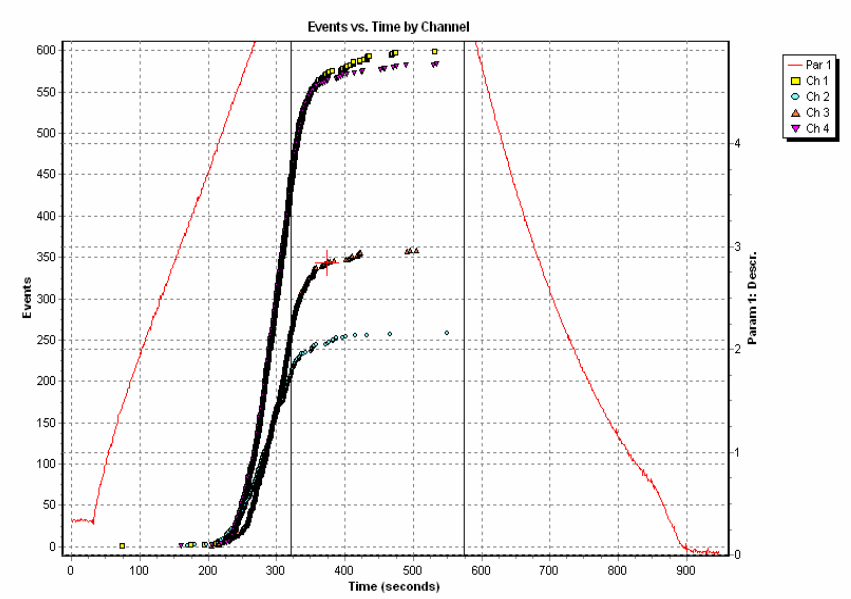

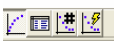

Figure 3. Typical cumulative events versus time curves for first arrival channel in a test with four channels (four $A E$ sensors). Hold pressure was 18,000 psi, which was 1.8 times operating pressure. The vertical lines mark the pressure hold region. This is the behavior of a good vessel. The cumulative events exhibits a strong negative exponential curvature with time during pressure hold. Each point represents an event and the four waveforms recorded for the event.
The shape of the cumulative events versus time curve during load hold demonstrates the stability of a composite. The shape of the cumulative events versus time curve during load hold exponent must be negative and be within a certain range of values and the fit must be within a range of $R^{2}$ values. A stable vessel will exhibit a cumulative curve with exponentially decaying curvature.

The shape of the cumulative events curve is similar for pressure vessels made of glass, Kevlar and carbon fiber HPC pressure vessels that exhibit a fiber dominated failure mode, which vessels are the subject here. This makes it very useful for determining stability of a vessel made according to a new manufacturing process or to catch an unintentional manufacturing process change.

A related acceptance criterion is the cumulative energy curve. It should also decay exponentially. The exponent must be negative and be within a certain range of values and the goodness of fit must be above a certain $\mathrm{R}^{2}$ value.

The derivative of the cumulative curve is called the decay curve, Figure 4. The exponent should be the same as for the cumulative curve. The decay curve is fit by binning events in time. It is sensitive to sudden changes in the sequence of binned events. Deviations are picked up by a low $\mathrm{R}^{2}$ goodness of the fit. Decay curves should be plotted for both the cumulative events and cumulative energy.

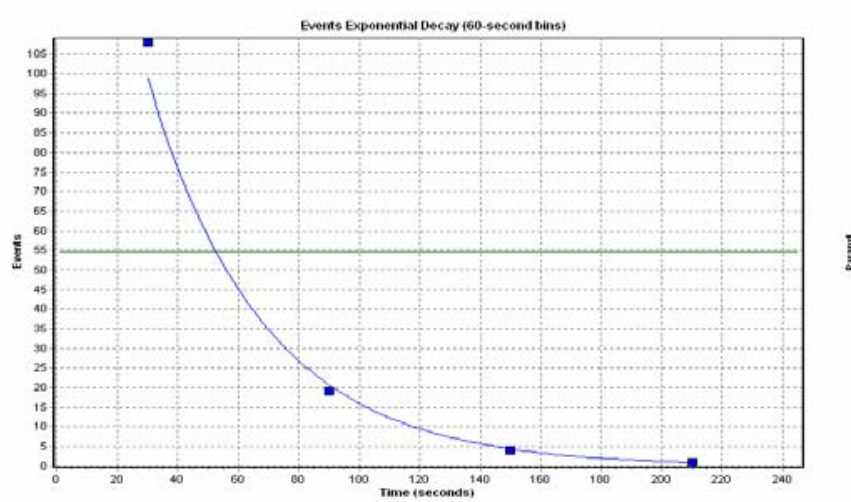

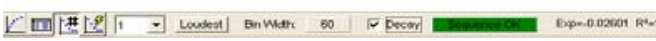

Figure 4. Event decay rate for data shows rate is exponentially approaching zero. Vessel is well-behaved.

Exponential fits are done by channel for pressure holds. B values are determined by the fit to

$$
\mathrm{y}=\mathrm{A} * \operatorname{EXP}(\mathrm{B} * \mathrm{t})+\mathrm{C} \text {. }
$$

The $B$ value is the shape of the cumulative curves. $C$ is an intercept and $\mathrm{A}$ is a scale factor. The time $\mathrm{t}$ should be equal intervals during the hold with events binned by time interval. $\mathrm{B}$ values for some composites range from -0.0001 to -0.1 . A prototype vessel provides the initial $\mathrm{B}$ value, provided that it behaves as expected, i.e., the cumulative $\mathrm{AE}$ events and energy decay with time in the load hold and the vessel burst pressure is satisfactory.

It is important that the person using this procedure be welltrained in AE techniques and have a good understanding of composite material behavior, as well as knowledge of the 
pressure vessel design and intended use. AE methods are very similar to those used in seismology. Wave motion is produced by a fracture event in the composite material. Waves propagate to sensors mounted on the surface of the pressure vessel and the waveforms are analyzed according to wave propagation theory. The waveforms of interest are the E (Extensional) and F (Flexural) plate waves.

Spectral content is related to the source. For example, mechanical rubbing on the vessel surface produces waves with low frequencies, while fiber breaks produce waves with high frequencies. In this procedure, analysis of waves is done mainly to distinguish and eliminate noise. Methods exist for identifying individual fracture sources, if more detailed knowledge of the sources is desired.

Similarly to cracks being blunted in a metal pressure vessel that sustains a given pressure, the composite material rapidly adapts to the stress concentrations due to all the fiber breaks (and matrix fractures) by redistributing the stresses to stronger sections. Unlike with steel where the crack blunting occurs nearly instantaneously (there is no known creep behavior in steel at room temperature), in composites there is time dependent behavior. The point of $\mathrm{AE}$ monitoring is to verify that stable redistribution is taking place. This is why counting $\mathrm{AE}$ events and observing the shape of the cumulative events versus time curve during load hold demonstrates the stability of a composite and is a very important technique. A related curve is the cumulative energy versus time during hold.

The source energy in an acoustic emission wave depends on the amount of motion at the source, i.e., the size of the disturbance to the wave propagation medium. Fiber breaks do not involve significant motion and are relatively low energy, especially below $80 \%$ - $90 \%$ of burst pressure. On the other hand, the motion of larger matrix cracks involves much more volume of material than a fiber break and are much more energetic. Matrix cracking along a fiber direction, sometimes called splitting, can be so energetic it becomes audible.

When doubt exists about the stability of the composite material, that is the emission persists and does not decay at a specified rate, or the energies of the emissions are not decaying during a load hold, then there is evidence that a serious stress concentration exists. This is not normal pressure vessel behavior. Waveform analysis of the AE waveforms may be used to determine the source of the events and vessel integrity may be assessed through engineering analysis. Other NDE techniques may be useful in determining or verifying the source of the emission.

\subsection{Testing Requirements}

All vessels are subjected to a hydrostatic pressure test and measurement of elastic expansion. Elastic expansion is perhaps the most accurate measure of whether the proper amount of fiber has been applied to the vessel. An acoustic emission measurement is also made at this time as discussed in section 3.6 of this paper.
Qualification testing is conducted to confirm the design and manufacturing process of the vessel. Qualification test units must be representative of production vessels. These tests subject the vessel to conditions that may be seen in service. All results of testing and examinations are documented in the Qualification Test Report.

Some qualification tests may be conducted on subscale vessels, such as using a reduced length if the test response would not be length dependent, or reduced diameter and length for tests that are materials based rather than size based. Similarly, design changes can be qualified by a reduced test matrix, such that tests are only required where performance is likely be affected by the design change.

When production commences, the first vessel of a lot is burst. A burst test is then conducted after every 200 vessels produced, or at least within one year of the start of production if less than 200 vessels are produced. Similarly, a pressure cycle test is conducted on one out of every 200 vessels produced.

Test failures must be investigated. If there is evidence of a fault in conducting the test, it may be repeated. If the test procedure was proper, the cause of failure must be investigated and corrective action taken, including, if appropriate, removal of some or all tanks tested since the previous production test.

The following qualification and production tests are required:

a) Hydraulic Proof Pressure Test. The hydraulic pressure is increased to 1.25 times the design pressure, and held for 30 minutes. This confirms there are no leaks and no permanent deformation of the tank.

b) Hydraulic Volumetric Expansion Test. The hydraulic pressure is increased to 1.25 times the design pressure. The elastic expansion is measured between $10 \%$ of the test pressure and the test pressure. The vessel is rejected if the elastic expansion is more than 110 percent of the most recent qualification or production burst test. The elastic expansion measurement provides a confirmation of the amount of fiber in the vessel.

If there is a loss of fiber, such as due to a strand being missing from a band, insufficient number of bands wound in a layer, or insufficient layers wound, it would be readily apparent in the elastic expansion measurement. If, for example, a strand broke during winding of a layer and was not discovered immediately, such that there was a 4 percent reduction in the amount of fiber on the vessel, the measured elastic expansion would be approximately 12 percent higher than the measurement on a correctly wound vessel.

c) Burst Test. The vessel is tested hydraulically, to destruction, by pressurizing at a rate of no more than $5 \mathrm{bar} / \mathrm{s}$ (70 psi/sec). Three units must be tested during qualification testing. The burst pressure must be at least 3.5 times design pressure for a glass fiber reinforced vessel, and at least 2.25 times design pressure for a carbon fiber reinforced vessel. The pressurization rate is limited to ensure that the pressure is not "spiked", and that the vessel actually sees the pressure as 
measured. This test confirms the basic strength of the vessel, and that the requirements for stress level will be met at the design pressure, to assure that the vessel not rupture during its design life.

d) Fatigue Test. The vessel is subjected to a hydraulic pressure cycle between 10 percent of design pressure to the design pressure for " $N$ " cycles. The value is " $N$ " depends on the number of cycles specified in the Design Specification and the number of tanks subjected to the design specification. The Fatigue Design Margin $\left(\mathrm{K}_{\mathrm{n}}\right)$, which is multiplied by the number of design cycles, is equal to 4.0 if only two tanks are tested, 3.5 if three tanks are tested, 3.0 if three tanks are tested, and 2.6 if five tanks are tested. The fatigue test provides assurance that the vessel will not leak or rupture during the intended service life.

e) Temperature Creep Test. Two vessels are hydraulically pressured to 1.25 times the design pressure and maintained for 2,000 hours. The test environment is held at 85C (185F) and a relative humidity of less than 50 percent. The vessels may not deform or unravel during the test, and must meet the requirements of the leak test and burst test after the 2,000 hour hold at temperature and pressure. The vessel tested may be a full diameter, shortened length subscale. This temperature creep test provides assurance that the vessel maintains its integrity when exposed to extreme temperature that may be seen in service.

f) Flaw Test. Two vessels have flaws cut into the vessel. One flaw is cut longitudinally, the other circumferentially. The cuts are at the same longitudinal position, but 120 degrees apart on the circumference. The flaw must be at least $1.27 \mathrm{~mm}$ (0.050 inch) deep, with a length equal to five times the composite thickness. The flaws may be made to a greater depth in accordance with the Manufacturing Specification if the fabricator wants to be able to allow a greater depth in its inspection criteria. The vessel tested may be a full diameter, shortened length subscale.

One of the vessels is subjected to the burst test, achieving a pressure at least 2 times the Design Pressure. The other vessel is subjected to a fatigue cycle test. This vessel may not rupture after 5000 cycles, and may not leak after 1000 cycles. If the vessel does leak after 1000 cycles, it is deemed to have passed the test. This test insures that there will not be a catastrophic failure mode in the event of a flaw due to the exterior of the vessel being cut or abraded in service. It is expected that the vessel will be inspected before 5000 pressure cycles would occur.

A study of flawed cylinder testing was made under the auspices of ASME Standards Technology LLC, with funding from the National Renewal Energy Laboratory (NREL). Flaws were cut into the vessels at depths up to 40 percent of the thickness. Some vessels were burst, others were cycles 10,000 or 20,000 times, and then burst. The burst pressure was reduced proportionally to the depth of cut, but the added cycles did not appreciably change the burst pressure [7]. g) Permeability Test. This test is required for vessels with non-metallic liners or welded metallic liners. The boss is subjected to twice the specified fitting installation torque before beginning the test. The vessel is filled to design pressure with a 5 percent hydrogen, 95 percent nitrogen mixture, and monitored for 500 hours to establish a steady state response. The permeation rate of hydrogen from this mixture must not exceed 0.15 standard cc per hour per liter water capacity of the vessel. The fraction of hydrogen and nitrogen was chosen for test safety, as it is a non-flammable mixture. The allowable permeation rate is chosen such that, with 100 percent hydrogen, the permeated gas would not reach a combustible level. Studies have shown that in a poorly ventilated garage space, the allowable permeation could safely be one to two orders of magnitude higher.

h) Leak Test. Acceptable method for testing include, but are not limited to, bubble testing using dry air or gas, or measurement of trace gases using a mass spectrometer. This confirms that there are no defects in that tank that would result in leakage of contents.

i) Torque Test on Nozzle Neck. The vessel is held so that it will not rotate during the test or, by the neck if required by the Fabricator's directions. The valve is inserted using 150 percent of the maximum recommended torque, then removed, and installed again with the same torque. The vessel tested may be a full diameter, shortened length subscale.

The threads and boss must show no significant deformation and remain with the drawing tolerances. The vessel may not leak or exceed the permeation requirement. This test gives assurance that the threads, boss, and boss/liner interface are not damaged during valve installation with higher than expected torques.

j) Penetration Test. The vessel is pressurized to design pressure with nitrogen or the contained gas. A $7.62 \mathrm{~mm}$ (30caliber) armor piercing bullet is used to impact the wall at an angle of approximately 45 degrees. The vessel tested may be a full diameter, shortened length subscale. The cylinder must not rupture as a result of the impact.

The penetration test, also referred to as a gunfire test, is intended to demonstrate non-shatterability of the vessel in the event the wall is penetrated during an impact. As the pressure of Class III vessels can be higher than many other pressure vessels, the wall may be too thick for the normal bullet to penetrate. In this case, experience in testing of similar vessels, using either multiple bullets or higher caliber/higher energy bullets, has shown that the vessel performance will be acceptable.

k) Environmental Test. One vessel is tested, including coating and protective layer if applicable. The upper surface of the vessel is subjected to an impact with controlled energy input in five locations, with each area exposed to a different fluid. These fluids are sulfuric acid, sodium hydroxide, methanol/gasoline, ammonium nitrate, and windshield washer fluid (methyl alcohol and water). 
The controlled impact models being hit with an object that would damage a protective resin layer and allow ingress of fluids. The fluids were chosen to represent the most aggressive fluids from different classes of fluids to which a vessel might reasonably be exposed during service [N6].

After the impact and fluid exposure, the vessels are pressure cycled 3000 times to 125 percent of design pressure, then held at the upper pressure, such that a the total exposure time is 48 hours. The vessel shall not rupture during the test. This test gives assurance that the structural materials will not be degraded significantly by exposure to extreme elements in the operating environment.

\subsection{Quality Program}

The Fabricator must develop and use a quality program that addresses the technical issues related to the manufacture of Class III vessels. The requirements of Section X Appendix 1 must be met. The Fabricator must be accredited to apply the Section X “RP” stamp.

The Fabricator must supply the certifications, specifications, and records of tests to the User as required. A Fabricator's Data Report must be completed for each vessel. A Qualification Test Report contains details of the laminate design and the laminate procedure specification.

The Fabricator keeps a copy of the Fabricator's Data Report until the date of expiration of the Class III vessel, or may register the vessel with the National Board of Boiler and Pressure Vessel Inspectors.

\subsection{DISCUSSION}

The new Section X Class III Code Rules address the need for new pressure vessels for hydrogen storage applications. Although initially targeted to serve the hydrogen applications, vessels designed and manufactured to these Rules could be safely used for other gases in other applications. Plans are being made to propose changes in Section X Appendix 8 to address these additional applications. The need for these new rules is reinforced in that inquiries have already been received regarding supply of vessels qualified to these new Rules.

\subsection{CONCLUSIONS}

The new Section X Class III Code Rules have been developed by the Project Team on Hydrogen Tanks and the Section X Committee based on significant industry experience. The qualification and production test requirements have been based on consensus use in standards to confirm safety and suitability of the vessel design. Production controls and inspections confirm that production vessels are constructed the same as those used for qualification testing.

\subsection{ACKNOWLEDGMENTS}

The authors would like to acknowledge the Project Team on Hydrogen Tanks, the Section X Committee, the staff of
ASME and ASME Standards Technology LLC, and NREL for their roles in developing of the new Section X Class III Code Rules.

\subsection{REFERENCES}

[1] Newhouse, N.L. and Webster, C.: Data Supporting Composite Tank Standards Development, ASME STP-PT-014.

[2] Newhouse, N.L., Johnson, D.B., and Baldwin, D.D.: "Design and Qualification of Advanced Composites for Marine Applications," paper OTC 8568, presented at the 1997 Offshore Technology Conference, Houston, Texas, 5-8 May 1997.

[3] Rana, M.D., Rawls, G.B. Sims, J.R. and Upitis, E.: Technical Basis and Application of New Rules on Fracture Control of High Pressure Hydrogen Vessel in ASME Section VIII, Division 3 Code, PVP2007-26023, Proceedings of 2007 ASME Pressure Vessels and Piping Conference, July 22-26, 2007, San Antonio, Texas, USA.

[4] Smith, J.H. Guidelines for In-Service Inspection of Composite Pressure Vessels, ASME STP-PT-023.

[5] Glaser, R.E., Moore, R.L. and Chiao, T.T.: "Life Estimation of an S-Glass/Epoxy Composite Under Sustained Tensile Loading," Composites Technology Review, Spring 1983, Vol. 5, No. 1.

[6] Robinson, E. Y.: "Design Prediction for Long-Term Stress Rupture Service of Composite Pressure Vessels," Aerospace Report No. ATR-92(2743)-1, The Aerospace Corporation, 1 December, 1991

[7] Makinson, J.D. and Newhouse, N.L. Compressed Hydrogen Performance Verification Flaw Testing of Fiber Reinforced Pressure Vessels. ASME STP-PT-043, 2010.

[8] Herridge, J.T., Stephens, D.R., et al: "Identification of Service Environment of NGV Fuel Cylinders”, Battelle Columbus Laboratories, Gas Research Institute Report GRI-94/0203, July 1994. 